\title{
The emergence of oral tadalafil as a once-daily treatment for pulmonary arterial hypertension
}

\author{
This article was published in the following Dove Press journal: \\ Vascular Health and Risk Management \\ 19 April 2010 \\ Number of times this article has been viewed
}

\author{
Jeremy A Falk \\ Kiran J Philip \\ Ernst R Schwarz \\ Cedars Sinai Women's Guild Lung \\ Institute, Cedars Sinai Heart Institute, \\ Cedars Sinai Medical Center, \\ Los Angeles, CA, USA
}

\begin{abstract}
Pulmonary hypertension $(\mathrm{PH})$ is found in a vast array of diseases, with a minority representing pulmonary arterial hypertension (PAH). Idiopathic PAH or PAH in association with other disorders has been associated with poor survival, poor exercise tolerance, progressive symptoms of dyspnea, and decreased quality of life. Left untreated, patients with PAH typically have a progressive decline in function with high morbidity ultimately leading to death. Advances in medical therapy for PAH over the past decade have made significant inroads into improved function, quality of life, and even survival in this patient population. Three classes of pulmonary artery-specific vasodilators are currently available in the United States. They include prostanoids, endothelin receptor antagonists, and phosphodiesterase type 5 (PDE5) inhibitors. In May 2009, the FDA approved tadalafil, the first once-daily PDE5 inhibitor for $\mathrm{PAH}$. This review will outline the currently available data on tadalafil and its effects in patients with PAH.
\end{abstract}

Keywords: PDE-5 inhibition, pulmonary hypertension, tadalafil

\section{Introduction}

Pulmonary arterial hypertension (PAH) is a rare disorder with reports estimating its prevalence at between 15 and 52 cases per one million patients. ${ }^{1,2}$ Pulmonary hypertension $(\mathrm{PH})$ has been defined differently based on the modality used to measure pulmonary pressures and hemodynamics. Generally considered the gold standard for the assessment of pulmonary hypertension, direct pulmonary artery catheterization with pressure measurements is preferred to less invasive techniques to confirm the suspected diagnosis. PAH is defined by a mean pulmonary artery pressure (mPAP) of more than $25 \mathrm{mmHg}$ at rest or of more than $30 \mathrm{mmHg}$ with exercise. In PAH, pulmonary capillary wedge pressure or left ventricular end diastolic pressure (in the absence of a mitral valve stenosis) is usually less than $15 \mathrm{mmHg}$. 3,4

Traditional classification of pulmonary hypertension largely differentiated patients with idiopathic or primary cases from patients with $\mathrm{PH}$ from secondary causes. This classification scheme had many limitations as it did not adequately describe underlying mechanisms of the disease and their implications for potential treatment options, based on the pathophysiology of the underlying conditions. In 1998, the World Health Organization (WHO) created a classification scheme, often referred to as the "Evian Classification," which described a variety of disorders causing pulmonary hypertension based on different mechanisms. ${ }^{5}$ This classification scheme was further refined in 2003 in Venice and most recently in 2008 at the 4th World Symposium on Pulmonary Hypertension in Dana Point, California (Table 1). ${ }^{6}$
Correspondence: Ernst R Schwarz,

Cedars Sinai Heart Institute, CSMC, 8700

Beverly Boulevard., Ste. 6215, Los Angeles, CA 90048 , USA

Tel + I 310-423-1866

Fax + I 310-423-1498

Email ernst.schwarz@cshs.org 
Table I Dana Point classification of pulmonary hypertension (PAH), 2008
I. Pulmonary arterial hypertension (PAH)
I.I. Idiopathic PAH

I.2. Heritable

1.2.I. BMPR2 (bone morphogenetic protein receptor type 2)

I.2.2. ALKI (activin receptor-like kinase type I), endoglin (with or without hereditary hemorrhagic telangiectasia)

1.2.3. Unknown

I.3. Drug- and toxin-induced

I.4. Associated with

I.4.I. Connective tissue diseases

I.4.2. HIV infection

1.4.3. Portal hypertension

I.4.4. Congenital heart diseases

I.4.5. Schistosomiasis

I.4.6. Chronic hemolytic anemia

1.5. Persistent pulmonary hypertension of the newborn

I. Pulmonary veno-occlusive disease (PVOD) and/or pulmonary capillary hemangiomatosis $(\mathrm{PCH})$

2. Pulmonary hypertension owing to left heart disease

2.I. Systolic dysfunction

2.2. Diastolic dysfunction

2.3. Valvular disease

3. Pulmonary hypertension owing to lung diseases and/or hypoxia

3.I. Chronic obstructive pulmonary disease

3.2. Interstitial lung disease

3.3. Other pulmonary diseases with mixed restrictive and obstructive pattern

3.4. Sleep-disordered breathing

3.5. Alveolar hypoventilation disorders

3.6. Chronic exposure to high altitude

3.7. Developmental abnormalities

4. Chronic thromboembolic pulmonary hypertension (CTEPH)

5. Pulmonary hypertension with unclear multifactorial mechanisms

5.I. Hematologic disorders: myeloproliferative disorders, splenectomy

5.2. Systemic disorders: sarcoidosis, pulmonary Langerhans cell histiocytosis: lymphangioleiomyomatosis, neurofibromatosis, vasculitis

5.3. Metabolic disorders: glycogen storage disease, Gaucher disease, thyroid disorders

5.4. Others: tumoral obstruction, fibrosing mediastinitis, chronic renal failure on dialysis

Notes: This is a recently updated classification scheme of pulmonary hypertension which emphasizes underlying pathophysiology and underlying implications for treatment. Adapted with permission from Simonneau G, Robbins IM, Beghetti M, et al. Updated clinical classification of pulmonary hypertension.J Am Coll Cardiol. 2009; 54(I Suppl):S43-54. ${ }^{6}$ Copyright $\odot 2009$ Elsevier.

The current WHO classification scheme divides PH into five groups: Group 1 represents disorders resulting in $\mathrm{PH}$ such as idiopathic $\mathrm{PH}$, familial forms of $\mathrm{PH}$, drug/toxininduced $\mathrm{PH}, \mathrm{PH}$ associated with connective tissue diseases,
HIV infection, portal hypertension, congenital heart disease, schistosomiasis, and chronic hemolytic anemia, as well as persistent pulmonary hypertension of the newborn. Group 2 includes causes of $\mathrm{PH}$ as a result of left sided heart disease. Group 3 includes patients with chronic hypoxemia and/or lung disease. Chronic thromboembolic disease is categorized in group 4 and group 5 is reserved for those diseases which have multifactorial mechanisms leading to $\mathrm{PH}$.

\section{Treatments for PAH}

Most recent pharmacologic treatments of $\mathrm{PH}$ have focused on group 1 or PAH. In fact, of the current Food and Drug Administration (FDA)-approved agents for the treatment of PH, all are approved for PAH (group 1) only. Current pharmacologic treatment for PAH include calcium channel blockers, prostanoids, endothelin receptor antagonists (ERA), and phosphodiesterase type 5 (PDE5) inhibitors (Table 2). The use of calcium channel blockers in PAH has generally been restricted due to limited benefits, significant side effects, and relatively narrow indications. ${ }^{3}$ Calcium channel blockers appear to benefit mainly patients with PAH with a positive vasodilator challenge, however, even in those patients, the long-term response to calcium channel blocker treatment is variable. $^{7}$

ERAs currently approved for use in the US include bosentan and ambrisentan. Endothelin-1 is a potent vasoconstrictor and mitogen likely causing vascular remodeling in susceptible individuals. Both bosentan and ambrisentan have been shown to significantly improve exercise capacity and hemodynamics in PAH. ${ }^{8-12}$ Bosentan is a nonselective endothelin receptor blocker, whereas ambrisentan blocks

Table 2 FDA-approved medications for pulmonary arterial hypertension

\begin{tabular}{|c|c|}
\hline Medication & Dose/Route \\
\hline Epoprostenol (Flolan ${ }^{\circledR}$ ) & $\begin{array}{l}\text { Start } 2 \mathrm{ng} / \mathrm{kg} / \mathrm{min} \mathrm{IV} \text { and titrate to } \\
\text { clinical effect }\end{array}$ \\
\hline Treprostinil (Remodulin ${ }^{\circledast} /$ Tyvaso $^{\circledR}$ ) & $\begin{array}{l}0.625-40 \mathrm{ng} / \mathrm{kg} / \mathrm{min} \text { IV/SQ } \\
\text { I8-54 } \mu \mathrm{g} \text { inhaled QID }\end{array}$ \\
\hline Iloprost (Ventavis ${ }^{\circledR}$ ) & $\begin{array}{l}2.5-5 \mu \mathrm{g} \text { nebulized inhaled solution } \\
\text { to } \mathrm{max} \text { of } 9 \text { doses/day }\end{array}$ \\
\hline Ambrisentan (Letairis ${ }^{\circledR}$ ) & 5-10 mg PO daily \\
\hline Bosentan $\left(\right.$ Tracleer $\left.^{\circledR}\right)$ & $62.5-125 \mathrm{mg}$ PO BID \\
\hline Sildenafil (Revatio ${ }^{\circledR}$ ) & $20 \mathrm{mg}$ PO TID \\
\hline Tadalafil $\left(\right.$ Adcirca $\left.^{\circledR}\right)$ & 40 mg PO daily \\
\hline
\end{tabular}

Notes: Seven medications are FDA approved for the treatment of PAH.Three classes of medications are represented here: prostanoids (epoprostenol, treprostinil, and iloprost), endothelin receptor antagonists (ambrisentan and bosentan), and phosphodiesterase type 5 inhibitors (sildenafil and tadalafil). 
only endothelin-A receptors. Liver function abnormalities have been noted with ERAs, in particular with bosentan, thus monthly liver function testing is required. ${ }^{3}$

Both parenteral and inhaled forms of prostacyclins are currently available for the treatment of PAH. Patients with PAH under produce prostacyclin, which functions to vasodilate, inhibit vascular proliferation, and inhibit platelet aggregation. Epoprostenol, a synthetic prostacyclin, was the first FDA-approved medication for the treatment of PAH. It remains the treatment of choice for advanced disease. Epoprostenol has a very short half-life and must be given continuously with an intravenous pump, typically with a starting dose of $2 \mathrm{ng} / \mathrm{kg} / \mathrm{min}$ intravenously and titrated upwards to desired clinical effect. Ambulatory pumps have made it possible to treat patients with severe PAH as outpatients. ${ }^{13}$ Epoprostenol has been shown to improve quality of life, exercise capacity, hemodynamics and even survival in PAH. ${ }^{14-17}$ Side effects include flushing, body aches, hypotension, and jaw pain. Treprostinil, available in intravenous, subcutaneous, and inhaled formulations, has a longer halflife than epoprostenol, thus allowing a wide variety of routes of delivery and may aid in improving compliance. ${ }^{18-20}$

PDE5 inhibitors have recently become an attractive first-line choice in the treatment of milder forms of PAH. Sildenafil was first FDA approved in the US for the treatment of erectile dysfunction (ED) in 1998. After its release for the use in ED, sildenafil was found to be an effective pulmonary artery vasodilator. ${ }^{21-23}$ In 2005 , sildenafil was approved for use in PAH at a dose of $20 \mathrm{mg} 3$ times daily, based in large part to the SUPER trial. ${ }^{24}$ There has been debate about the appropriate dosing of sildenafil for $\mathrm{PAH}$ as many studies have used dosing several-fold higher than the current FDA approved dosing. ${ }^{25-31}$ While a clear doseresponse effect of escalating dosing of sildenafil has not been shown in terms of improvements in exercise capacity, quality of life, or hemodynamics, long-term data in patients receiving $80 \mathrm{mg} 3$ times daily for 1 year have shown sustained benefit with minimal adverse effects. ${ }^{24}$ Similar data for the $20 \mathrm{mg}$ dose do not exist. Additionally, when used in combination with ERAs, it has been shown that there are decreased plasma levels of sildenafil, providing more rationale for higher dosages of sildenafil. ${ }^{32}$ Sildenafil has been shown to improve symptoms of PAH, improve exercise tolerance, improve hemodynamics, and to improve quality of life. ${ }^{24,28,29}$ Sildenafil inhibits the breakdown of cyclic guanosine monophosphate (cGMP) thus increasing the effects of nitric oxide (NO) resulting in pulmonary vasodilation and inhibition of smooth muscle growth. The mechanism of action of PDE5 inhibitors will be discussed in more detail later. Tadalafil, another PDE5 inhibitor approved for PAH earlier this year, is a once daily medication used at a dose of $40 \mathrm{mg}$ daily. Tadalafil, like sildenafil and vardenafil, was originally developed and marketed as a pharmacologic treatment for erectile dysfunction. Vardenafil appears to be less efficacious than either sildenafil or tadalafil for the treatment of PAH. ${ }^{33}$ Tadalafil's longer half-life of 17.5 hours compared with that of sildenafil at 4 to 5 hours allows for a once-daily dosing.

\section{PDE-5 inhibitors for the treatment of erectile dysfunction}

Sildenafil was FDA approved in 1998 as the first PDE5 inhibitor for the treatment of ED. Shortly after this, two other PDE5 inhibitors, tadalafil and vardenafil, were approved for the treatment of ED. While very few comparative data exist for the various PDE5 inhibitors, there is a large body of double-blind placebo-controlled trials for the various agents. ${ }^{34} \mathrm{~A}$ recent meta-analysis showed consistently beneficial short-term efficacy of PDE5 inhibitors in the treatment of ED with good safety profiles. ${ }^{34}$ Efficacy of treatment for ED is typically based on several validated measures of male sexual performance. ${ }^{34}$ The International Index of Erectile Function Erectile Functional Domain (IIEF EF) is a scoring system numbered 1-30 with higher numbers correlating with improved sexual function. ${ }^{35}$ Another assessment tool is the use of questions 2 and 3 of the Sexual Encounter Profile (SEP), which ask first whether or not an adequate erection is obtained to initiate sexual intercourse and second whether or not intercourse is able to be completed. ${ }^{36}$ The Global Assessment Question (GAQ) asks, "Has the treatment you have been taking during this study improved your erection?" 36

Approximately 28 randomized controlled trials (RCTs) observing the efficacy of tadalafil in ED have been recently identified. ${ }^{34}$ Two recent multi-centered placebo-controlled studies showed marked improvements in sexual performance with the addition of tadalafil given at a daily dose of $20 \mathrm{mg} .37,38$ Skoumal et al randomized 443 men with ED to receive either tadalafil or placebo. ${ }^{37}$ Patients in the tadalafil group had significant improvements in sexual function as measured by IIEF EF, SEP, and GAQ. In fact, $64 \%$ of patients receiving tadalafil had normal IIEF EF domain scores as opposed to only $16 \%$ for those receiving placebo. Porst et al studied 348 patients randomized to tadalafil or placebo for two 4-week treatment intervals. ${ }^{38}$ Patients were asked to attempt sexual intercourse 24 and 36 hours after dosing with a primary endpoint being 
the ability to complete sexual intercourse to completion. At 36 hours, $59.2 \%$ of patients receiving tadalafil were able to complete intercourse compared with only $28.3 \%$ in the placebo arm, $P<0.001$. Similar results were observed at 24 hours with successful intercourse reported as $52.9 \%$ and $29.1 \%$, respectively $(P<0.001)$. Another study conducted at 15 US centers randomized 287 patients to receive oncedaily tadalafil at $5 \mathrm{mg}, 2.5 \mathrm{mg}$, or placebo for 24 weeks. ${ }^{39}$ Primary endpoint was a change in IIEF EF Domain score and response to SEP question 2 and 3. Significant improvements in ED were reported in all 3 endpoints with low incidence of adverse events.

The longer half-life of tadalafil (17.5 hours) when compared with sildenafil (4 hours) may represent an attractive option to some patients as it may allow for less frequent dosing and a more sustained benefit. An unbiased, rigorously designed head to head trial among currently approved PDE5 inhibitors for the treatment of ED does not currently exist. Four head to head trials of varying quality are currently published, of which three were funded by Eli Lilly. ${ }^{40-43}$ Eardley and colleagues conducted a 12-week, open-label, cross-over study comparing tadalafil (10 or $20 \mathrm{mg}$ ) to sildenafil (25 mg, $50 \mathrm{mg}$, or $100 \mathrm{mg}) .{ }^{40}$ No differences were found in IIEF EF domain or SEP 2; however there was a small but statistically significant difference in SEP 3 responses favoring tadalafil (72\% vs. 77\%, $P=0.003$ ). Additionally, at the conclusion of the study, $71 \%$ of patients preferred tadalafil to sildenafil. Two other double-blinded cross-over studies comparing sildenafil $50 \mathrm{mg}$ and tadalafil $20 \mathrm{mg}$ showed similar patient preference for tadalafil at the conclusion of the study; however, no benefit in efficacy was reported ${ }^{41,42}$ In a single non-industry sponsored comparison trial of sildenafil (100 mg), vardenafil (20 mg), and tadalafil (20 mg), 132 patients were prospectively enrolled in an open-label, cross over trial over 45 to 60 days with patient drug preference the primary outcome. ${ }^{43}$ At the end of the trial, 52\% preferred tadalafil, 28\% chose sildenafil, and $20 \%$ chose tardenafil. In terms of efficacy, tadalafil was statistically better than vardenafil measured both by IIEF and the Erectile Dysfunction Inventory for Treatment Satisfaction (EDITS) Questionnaire. A statistically significant difference in favor of tadalafil was also observed when compared to sildenafil as measured by the EDITS questionnaire. While there appears to be a trend towards the superiority of tadalafil over other PDE5 inhibitors for the treatment of ED, these results must be interpreted with caution. Half of these studies were open label and therefore subject to potential patient and investigator bias. ${ }^{40,43}$ Additionally, two studies used a maximum dose of sildenafil of $50 \mathrm{mg}$, which may represent a lower effective dose when compared directly with $20 \mathrm{mg}$ of tadalafil. ${ }^{41,42}$

\section{Pharmacology of tadalafil}

Many potential targets for therapeutic intervention in $\mathrm{PAH}$ have been identified. ${ }^{44} \mathrm{NO}$ formation in pulmonary artery endothelium is needed to promote pulmonary artery vasodilation and inhibition of smooth muscle cell proliferation. ${ }^{45}$ The production of cyclic guanosine monophosphate (cGMP) by activation of guanylate cyclase by NO in turn activates protein kinase $\mathrm{G}$ (PKG) that decreases pulmonary artery smooth muscle cell calcium and potassium levels leading to pulmonary artery vasodilation, decreased smooth muscle cell proliferation, and increased apoptosis of pulmonary artery smooth muscle cells. ${ }^{31}$ Patients with PAH have been shown to have both decreased nitric oxide production from the pulmonary artery endothelium and to have increased PDE5 expression in the pulmonary artery smooth muscle cells. ${ }^{46-48}$ The combined effects of decreased nitric oxide production and increased PDE5 expression ultimately promote pulmonary artery vasoconstriction and increased pulmonary vascular resistance. As PDE5 leads to degradation of cGMP, a selective PDE5 inhibitor would have numerous downstream benefits including pulmonary artery vasodilation, decreased pulmonary vascular resistance and ultimately increased cardiac output. Additionally, PDE5 inhibitors may augment right ventricular function though their inhibition of phosphodiesterase $3 .^{49}$

Phosphodiesterase type 5 is located primarily in pulmonary artery smooth muscle cells and in the penile circulation. Its main role is to degrade cGMP located in these tissues. The relative paucity of PDE5 in the systemic vasculature makes this an attractive therapeutic target as one would expect minimal systemic vasodilation as opposed to nonselective vasodilators such as calcium channel blockers which cause prohibitive hypotension in most patients with PAH. ${ }^{3}$

Serum concentrations of tadalafil reach a maximum 2 to 8 hours after ingestion of $40 \mathrm{mg}$ with a mean terminal halflife of 35 hours in patients with PAH. Tadalafil is predominantly metabolized by the liver by CYP3A and eliminated primarily in the feces and urine..$^{50,51}$ Unlike sildenafil, it is recommended that patients with mild-to-moderate renal or hepatic dysfunction undergo a dose adjustment to $20 \mathrm{mg}$ daily. ${ }^{31}$ As tadalafil is metabolized by CYP3A, inhibitors of the enzyme such as clarithromycin may lead to elevated serum concentrations. ${ }^{50}$ Combined usage of bosentan and 
tadalafil has been shown to lead to a $41.5 \%$ decrease in the serum levels of tadalafil with no effect on bosentan. ${ }^{52}$ Similar effects of combined use of tadalafil and ambrisentan have not been observed. ${ }^{53}$

\section{PDE-5 inhibition for the treatment of PAH}

Numerous studies have shown that sildenafil is efficacious in improving hemodynamics, improving exercise tolerance, and improving quality of life. ${ }^{21-24,28,29}$ Limited by study size and design, sildenafil, has not been shown to alter the natural history of PAH or to improve survival. Sildenafil's short half-life necessitates multiple daily dosing schedules and the currently approved dose of $20 \mathrm{mg} 3$ times daily may be inadequate for some patients.

Tadalafil has a longer half-life than sildenafil, thus allowing once-daily dosing. Starting in 2004, scattered case reports and small case series detailed the successful use of tadalafil for patients with PAH. An initial report in 2004 by Palmieri et al detailed the use of $20 \mathrm{mg}$ tadalafil given every other day in a 72-year-old female patient with PAH who failed epoprostenol infusion. ${ }^{54}$ The patient ultimately showed improvements in hemodynamics (pulmonary artery systolic pressure by echocardiogram went from $105 \mathrm{mmHg}$ at baseline to $65 \mathrm{mmHg}$ six months later), functional class (New York Heart Association class IV to II over 6 months), and improved gas exchange (partial pressure of oxygen to fraction of inhaled oxygen ratio went from 150 to $300 \mathrm{mmHg}$ ). Several other case reports using similar doses had similar results: In 2008, Tay and colleagues reported a case series of 12 patients with PAH who were voluntarily changed from sildenafil at a dose of 100 to $150 \mathrm{mg} /$ day to 10 to $20 \mathrm{mg} /$ day of tadalafil. ${ }^{55}$ Two small series describing the use of combination therapy with tadalafil have been published. The first published in 2008 by Bendayan et al details the combined use of prostacyclins and tadalafil. The addition of tadalafil to prostacyclins improved the 6-minute walk distance by nearly $60 \mathrm{~m}$ and improved functional status in 3 of 4 patients. ${ }^{56}$ Faruqi and colleagues reported the use of combined tadalafil and sitaxentan (a selective ERA approved in Europe and Australia) in 3 patients with PAH. ${ }^{57}$ Modest benefits in mean pulmonary artery pressure and 6-minute walk distance were noted after a minimum of 6 months, and, importantly, no serious adverse effects were reported. Given the clinical success of sildenafil in the treatment of PAH and the observed effects of small case series utilizing tadalafil, larger, prospective trials involving tadalafil were inevitable.

\section{Comparisons between PDE-5 inhibitors}

In general, head to head comparisons of various PDE5 inhibitors and their effect on the pulmonary circulation are lacking. Ghofrani et al compared the acute effects on hemodynamics and gas exchange of sildenafil $(50 \mathrm{mg})$, vardenafil $(10 \mathrm{mg}$ and $20 \mathrm{mg}$ ), and tadalafil (20 mg, $40 \mathrm{mg}$, and $60 \mathrm{mg}$ ) on patients with PAH. ${ }^{33} 60$ patients with New York Heart Association (NYHA) class II to IV symptoms were randomized to receive sildenafil, vardenafil, or tadalafil acutely after receiving short-term inhaled NO. After 120 minutes, all three PDE5 inhibitors showed significant reductions in mean pulmonary artery pressure with a range of $-10.0 \mathrm{mmHg}$ to $-18.3 \mathrm{mmHg}$. Only sildenafil and tadalafil were shown to be selective pulmonary vasodilators rather than systemic vasodilators (change in PVR/SVR ratio of -9.3 to -16.0 ), and only sildenafil was shown to improve oxygenation with an increase in the partial pressure of arterial oxygen of $8.9 \mathrm{mmHg}$. The authors postulated that the varying effects on hemodynamics and oxygenation were a result of different affinities of the drugs for other PDE subgroups other than 5, which may affect the pulmonary and systemic vasculature differently.

\section{Clinical trials of tadalafil in PAH}

In the only randomized, placebo-controlled study examining the use of tadalafil in PAH, Galiè and colleagues reported the effects of tadalafil alone or in combination with bosentan in the treatment of PAH (PHIRST trial). ${ }^{58}$ Four hundred and six patients were randomized to placebo, 2.5, 10, 20, or $40 \mathrm{mg}$ of tadalafil daily and followed for 16 weeks. Fifty-three percent of enrolled patients were taking bosentan at the time of enrollment. The primary endpoint was the change from baseline in the 6-minute walk test (6MWT) (Figure 1). Only patients randomized to $40 \mathrm{mg}$ of tadalafil achieved the predetermined level of statistical significance $(P<0.01)$ with an improvement in 6MWT of $33 \mathrm{~m}(95 \% \mathrm{CI}, 15-50 \mathrm{~m})$. Patients not taking bosentan improved by $44 \mathrm{~m}$ (95\% CI, 20-69 m), and those taking bosentan improved by $23 \mathrm{~m}$ ( $95 \% \mathrm{CI}-2$ to $48 \mathrm{~m}$ ). A review of secondary endpoints indicated improvements in time to clinical worsening, incidence of clinical worsening and health related quality of life. The authors suggested a possible drug-drug interaction with bosentan and tadalafil resulting in lower plasma levels of tadalafil, thus explaining the blunted response of tadalafil when used in combination with bosentan..$^{52,58}$

Data from a long-term extension study of the PHIRST trial has yet to be published. ${ }^{58}$ Tadalafil was generally well 


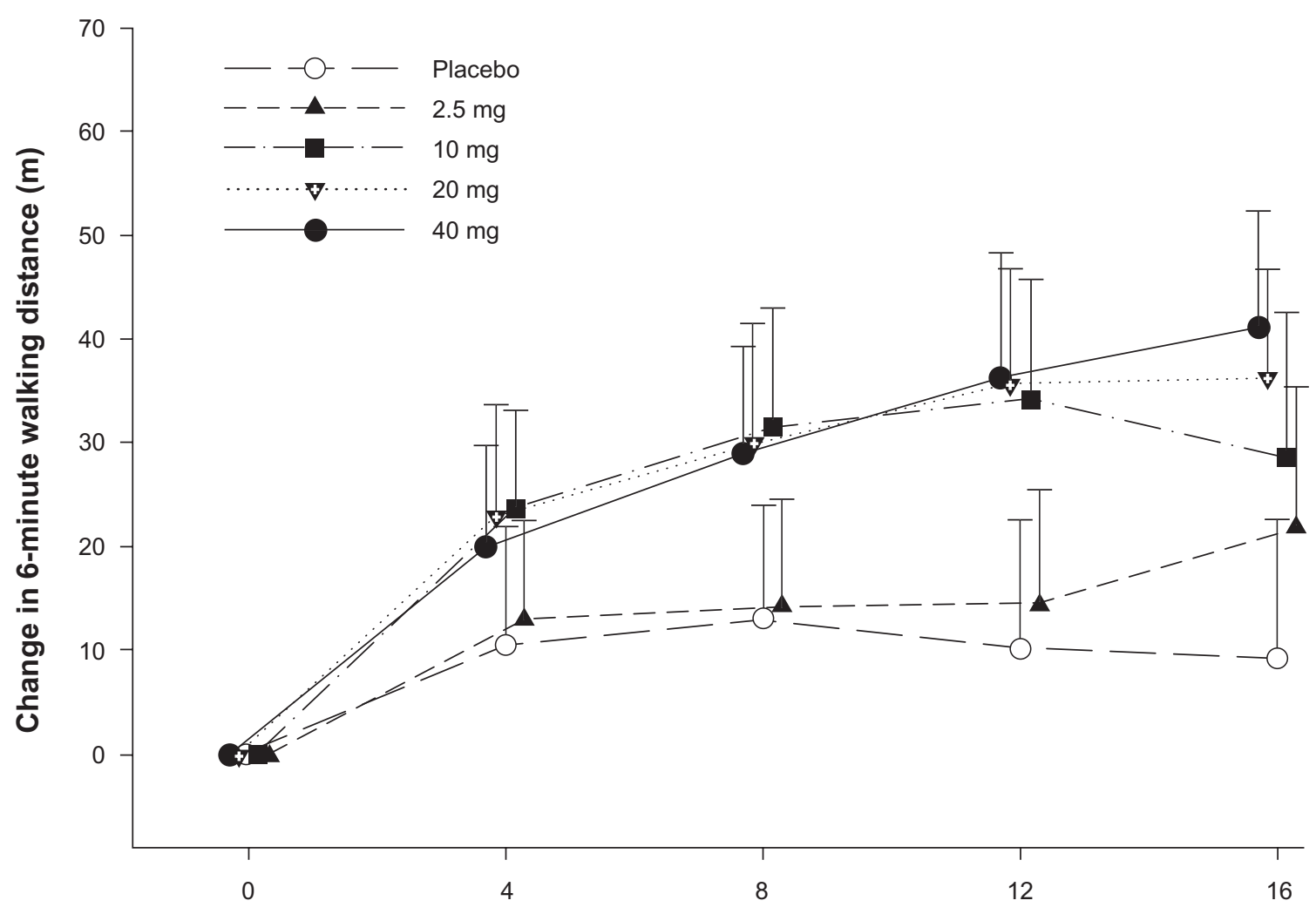

Weeks

Figure I Change in 6-minute walk distance over 16 weeks, tadalafil versus placebo: results of a 16-week randomized placebo controlled trial of tadalafil for the treatment of pulmonary artery hypertension. Significant improvements in 6-minute walk distance were observed in patients receiving 10,20 and 40 mg daily of tadalafil compared with placebo.

Notes: $P=0.047,0.028$, and $<0.001$, respectively; $\mathrm{N}=392$ patients, error bars represent $95 \%$ confidence intervals. Patients were randomized to one of five groups: placebo, $2.5 \mathrm{mg}, 10 \mathrm{mg}, 20 \mathrm{mg}$, or $40 \mathrm{mg}$ of tadalafil daily. Reproduced with permission from Galiè N, Brundage BH, Ghofrani HA, et al; Pulmonary Arterial Hypertension and Response to Tadalafil (PHIRST) Study Group. Tadalafil therapy for pulmonary arterial hypertension. Circulation. 2009; I I 9(22):2894-903. ${ }^{58}$ Copyright @ 2009 Lippincott Williams \& Wilkins.

tolerated with the most common side effects being headache, myalgias, and flushing. ${ }^{58} \mathrm{~A}$ second study published using the initial PHIRST data showed that patients receiving $40 \mathrm{mg}$ daily of tadalafil for PAH had significant improvements in quality of life compared with placebo. ${ }^{59}$ Self-reported health status and patient reported health-related quality of life using the Short Form 36 (SF-36) and EuroQOL (EQ-5D) were measured at baseline, week 8 and week 16. Interestingly, improvements observed in 6MWT did not correlate with improvements in quality of life measures.

There remain several unanswered questions regarding the use tadalafil in PAH. Mortality benefit for PAH which has only been shown only with the use of epoprostenol, is not known for tadalafil or other PDE5 inhibitors. ${ }^{14,15}$ Small sample size, short trial duration, and the relative rarity of PAH has made studying survival challenging. A recent metaanalysis examining the impact of treatment on PAH utilizing prostanoids, ERAs, and PDE5 inhibitors was recently published. ${ }^{60}$ Twenty-one randomized controlled trials were included in the analysis which showed an overall relative risk of mortality of $0.57(0.35,0.93)$ when receiving $\mathrm{PAH}$ specific therapy compared with placebo. Subset analysis revealed 5 RCTs which utilized PDE5 inhibitors (all using sildenafil - PHIRST data not included). There was a relative risk of death of $0.39(0.14,1.05)$ compared with placebo when patients were given PDE5 inhibitors, which nearly met statistical significance. This meta-analysis, while provocative, is limited by the relatively short duration of included studies and caution must be made in attributing a potential survival benefit to the use of tadalafil for PAH as the PHIRST data were not included.

\section{Conclusion}

The availability of several classes of PAH specific medications has revolutionized the treatment of PAH over the past two decades. Improvements in symptoms, exercise tolerance, 
quality of life, and survival have transformed the management this patient population from that of hopelessness to one of great promise. Tadalafil, the first once-daily PDE5 inhibitor FDA approved for the treatment of PAH, has been shown to improve exercise tolerance, pulmonary hemodynamics, and quality of life. The drug is well tolerated and carries with it a favorable side effect profile. Preliminary data on its use in combination therapy have been promising. Longer-term studies examining the durability of its benefits are ongoing. Lastly, the role of tadalafil in patients with pulmonary hypertension in groups II-V has not been clearly defined, with more studies needed to establish a role, if any, in these patient populations.

\section{Disclosures}

The authors declare no conflicts of interest.

\section{References}

1. Humbert M, Sitbon O, Chaouat A, et al. Pulmonary arterial hypertension in France: results from a national registry. Am J Respir Crit Care Med. 2006;173:1023-1030.

2. Peacock AJ, Murphy NF, McMurray JJ, Caballero L, Stewart S. An epidemiological study of pulmonary arterial hypertension. Eur Respir J. 2007;30:104-109.

3. Chin KM, Rubin LJ. Pulmonary Arterial Hypertension. J Am Coll Cardiol. 2008;51;1527-1538.

4. Barst RJ, McGoon M, Torbicki A, et al. Diagnosis and differential assessment of pulmonary arterial hypertension. J Am Coll Cardiol. 2004;43(12 Suppl S):40S-47S.

5. Fishman AP. Clinical classification of pulmonary hypertension. Clin Chest Med. 2001;22:385-391.

6. Simonneau G, Robbins IM, Beghetti M, et al. Updated clinical classification of pulmonary hypertension. J Am Coll Cardiol. 2009;54(1 Suppl): S43-S54.

7. Sitbon O, Humbert M, Jais X, et al. Long-term response to calcium channel blockers in idiopathic pulmonary arterial hypertension. Circulation. 2005;111:3105-3111.

8. Rubin LJ, Badesch DB, Barst RJ, et al. Bosentan therapy for pulmonary arterial hypertension. N Engl J Med. 2002;346:896-903.

9. Channick R, Badesch DB, Tapson VF, et al. Effects of the dual endothelin receptor antagonist bosentan in patients with pulmonary hypertension: a placebo-controlled study. J Heart Lung Transplant. 2001;20:262-263.

10. Galiè N, Olschewski H, Oudiz RJ, et al. Ambrisentan in Pulmonary Arterial Hypertension, Randomized, Double-Blind, Placebo-Controlled, Multicenter, Efficacy Studies (ARIES) Group. Ambrisentan for the treatment of pulmonary arterial hypertension: results of the ambrisentan in pulmonary arterial hypertension, randomized, double-blind, placebocontrolled, multicenter, efficacy (ARIES) study 1 and 2. Circulation. 2008;117:3010-3019.

11. McLaughlin VV, Sitbon O, Badesch DB, et al. Survival with first-line bosentan in patients with primary pulmonary hypertension. Eur Respir J. 2005;25:244-249.

12. Sitbon O, McLaughlin VV, Badesch DB, et al. Survival in patients with class III idiopathic pulmonary arterial hypertension treated with first line oral bosentan compared with an historical cohort of patients started on intravenous epoprostenol. Thorax. 2005;60:1025-1030.

13. Rubin LJ, Mendoza J, Hood M, et al. Treatment of primary pulmonary hypertension with continuous intravenous prostacyclin (epoprostenol). Results of a randomized trial. Ann Intern Med. 1990;112:485-491.
14. Barst RJ, Rubin LJ, McGoon MD, Caldwell EJ, Long WA, Levy PS. Survival in primary pulmonary hypertension with long-term continuous intravenous prostacyclin. Ann Intern Med. 1994;121:409-415.

15. Barst RJ, Rubin LJ, Long WA, et al. A comparison of continuous intravenous epoprostenol (prostacyclin) with conventional therapy for primary pulmonary hypertension. The Primary Pulmonary Hypertension Study Group. N Engl J Med. 1996;334:296-302.

16. Shapiro SM, Oudiz RJ, Cao T, et al. Primary pulmonary hypertension: improved long-term effects and survival with continuous intravenous epoprostenol infusion. J Am Coll Cardiol. 1997;30: 343-349.

17. Higenbottam T, Butt AY, McMahon A, Westerbeck R, Sharples L. Longterm intravenous prostaglandin (epoprostenol or iloprost) for treatment of severe pulmonary hypertension. Heart. 1998;80:151-155.

18. Tapson VF, Gomberg-Maitland M, McLaughlin VV, et al. Safety and efficacy of IV treprostinil for pulmonary arterial hypertension: a prospective, multicenter, open-label, 12-week trial. Chest. 2006;129: 683-688.

19. Simonneau G, Barst RJ, Galie N, et al. Continuous subcutaneous infusion of treprostinil, a prostacyclin analogue, in patients with pulmonary arterial hypertension: a double-blind, randomized, placebo-controlled trial. Am J Respir Crit Care Med. 2002;165:800-804.

20. Barst RJ, Galie N, Naeije R, et al. Long-term outcome in pulmonary arterial hypertension patients treated with subcutaneous treprostinil. Eur Respir J. 2006;28:1195-1203.

21. Prasad S, Wilkinson J, Gatzoulis MA. Sildenafil in primary pulmonary hypertension. N Engl J Med. 2000;343:1342.

22. Michelakis E, Tymchak W, Lien D, Webster L, Hashimoto K, Archer S. Oral sildenafil is an effective and specific pulmonary vasodilator in patients with pulmonary arterial hypertension: comparison with inhaled nitric oxide. Circulation. 2002;105:2398-2403.

23. Sastry BKS, Narasimhan C, Reddy NK, Raju BS. Clinical efficacy of sildenafil in primary pulmonary hypertension, I: a randomized, placebo- controlled, double-blind, crossover study. J Am Coll Cardiol. 2004;43:1149-1153.

24. Galiè N, Ghofrani HA, Torbicki A, et al. Sildenafil citrate therapy for pulmonary arterial hypertension. $N$ Engl J Med. 2005;353: 2148-2157.

25. Hoeper MM, Markevych I, Spiekerkoetter E, Welte T, Niedermeyer J. Goal-oriented treatment and combination therapy for pulmonary arterial hypertension. Eur Respir J. 2005;26:858-863.

26. Hoeper MM, Welte T. Sildenafil citrate therapy for pulmonary arterial hypertension. N Engl J Med. 2006;354:1091-1093.

27. Simonneau G, Rubin LJ, Galie N, et al; for the PACES Study Group. Addition of sildenafil to long-term intravenous epoprostenol therapy in patients with pulmonary arterial hypertension: a randomized trial. Ann Intern Med. 2008;149:521-530.

28. Pepke-Zaba J, Gilbert C, Collings L, Brown MCJ. Sildenafil improves health-related quality of life in patients with pulmonary arterial hypertension. Chest. 2008;133:183-189.

29. Singh T, Rohit M, Grover A, Malhotra S, Vijayvergiya R. A randomized, placebo-controlled, double-blind, crossover study to evaluate the efficacy of oral sildenafil therapy in severe pulmonary artery hypertension. Am Heart J. 2006;151:851.e1-851.e5

30. Authors/Task Force Members, Galie N, Hoeper MM, Humbert M, et al. ESC Committee for Practice Guidelines (CPG), Vahanian A, Auricchio A, Bax J, et al. Guidelines for the diagnosis and treatment of pulmonary hypertension: The Task Force for the Diagnosis and Treatment of Pulmonary Hypertension of the European Society of Cardiology (ESC) and the European Respiratory Society (ERS), endorsed by the International Society of Heart and Lung Transplantation (ISHLT). Eur Heart J. 2009;30:2493-2537.

31. Archer SL, Michelakis ED. Phosphodiesterase type 5 inhibitors for pulmonary arterial hypertension. N Engl J Med. 2009;361:1864-1871.

32. Paul GA, Gibbs JS, Boobis AR, Abbas A, Wilkins MR. Bosentan decreases the plasma concentration of sildenafil when coprescribed in pulmonary hypertension. Br J Clin Pharmacol. 2005;60:107-112. 
33. Ghofrani HA, Voswinckel R, Reichenberger F, et al. Differences in hemodynamic and oxygenation responses to three different phosphodiesterase- 5 inhibitors in patients with pulmonary arterial hypertension: a randomized prospective study. J Am Coll Cardiol. 2004;44: $1488-1496$.

34. Tsertsvadze A, Fink HA, Yazdi F, et al. Oral phosphodiesterase-5 inhibitors and hormonal treatments for erectile dysfunction: a systematic review and meta-analysis. Ann Intern Med. 2009;151:650-661.

35. Rosen RC, Riley A, Wagner G, Osterloh IH, Kirkpatrick J, Mishra A. The international index of erectile function (IIEF): a multidimensional scale for as- sessment of erectile dysfunction. Urology. 1997;49:822-830.

36. Brock GB, McMahon CG, Chen KK, et al. Efficacy and safety of tadalafil for the treatment of erectile dysfunction: results of integrated analyses. $J$ Urol. 2002;168:1332-1336.

37. Skoumal R, Chen J, Kula K, Breza J, Calomfirescu N, Basson BR, et al. Efficacy and treatment satisfaction with on-demand tadalafil (Cialis) in men with erectile dysfunction. Eur Urol. 2004;46:362-369.

38. Porst H, Padma-Nathan H, Giuliano F, Anglin G, Varanese L, Rosen R. Efficacy of tadalafil for the treatment of erectile dysfunction at 24 and 36 hours after dosing: a randomized controlled trial. Urology. 2003;62:121-125

39. Rajfer J, Aliotta PJ, Steidle CP, Fitch WP 3rd, Zhao Y, Yu A. Tadalafil dosed once a day in men with erectile dysfunction: a randomized, double-blind, placebo-controlled study in the US. Int J Impot Res. 2007;19:95-103.

40. Eardley I, Mirone V, Montorsi F, Ralph D, Kell P, Warner MR, et al. An open-label, multicentre, randomized, crossover study comparing sildenafil citrate and tadalafil for treating erectile dysfunction in men naïve to phosphodiesterase 5 inhibitor therapy. BJU Int. 2005;96:1323-1332.

41. von Keitz A, Rajfer J, Segal S, Murphy A, Denne J, Costigan T, et al. A multicenter, randomized, double-blind, crossover study to evaluate patient pref- erence between tadalafil and sildenafil. Eur Urol. 2004:45:499-507.

42. Govier F, Potempa AJ, Kaufman J, Denne J, Kovalenko P, Ahuja S. A multicenter, randomized, double-blind, crossover study of patient preference for tadalafil $20 \mathrm{mg}$ or sildenafil citrate $50 \mathrm{mg}$ during initiation of treatment for erectile dysfunction. Clin Ther. 2003;25:2709-23.

43. Tolrà JR, Campaña JM, Ciutat LF, Miranda EF. Prospective, randomized, open-label, fixed-dose, crossover study to establish preference of patients with erectile dysfunction after taking the three PDE-5 inhibitors. J Sex Med. 2006;3:901-909.

44. Humbert M, Sitbon O, Simonneau G. Treatment of pulmonary arterial hypertension. $N$ Engl J Med. 2004;351:1425-1436.

45. Budhiraja R, Tuder RM, Hassoun PM. Endothelial dysfunction in pulmonary hypertension. Circulation. 2004;109:159-165.

46. Giaid A, Saleh D. Reduced expression of endothelial nitric oxide synthase in the lungs of patients with pulmonary hypertension. $N$ Engl J Med. 1995;333:214-221.
47. Murray F, MacLean MR, Pyne NJ. Increased expression of the cGMP-inhibited cAMP-specific (PDE3) and cGMP binding cGMPspecific (PDE5) phosphodiesterases in models of pulmonary hypertension. Br J Pharmacol. 2002;137:1187-1194.

48. Wharton J, Strange JW, Møller GM, et al. Antiproliferative effects of phosphodi- esterase type 5 inhibition in human pulmonary artery cells. Am J Respir Crit Care Med. 2005;172:105-113.

49. Nagendran J, Archer SL, Soliman D, et al. Phosphodiesterase type 5 is highly expressed in the hypertrophied human right ventricle, and acute inhibition of phosphodiesterase type 5 improves contractility. Circulation. 2007;116:238-248.

50. Tadalafil (Adeirca) for pulmonary arterial hypertension. Med Lett Drugs Ther. 2009;51:87-88.

51. Forgue ST, Patterson BE, Bedding AW, et al. Tadalafil pharmacokinetics in healthy subjects. Br J Clin Pharmacol. 2006;61:280-288.

52. Wrishko RE, Dingemanse J, Yu A, Darstein C, Phillips DL, Mitchell MI. Pharmacokinetic interaction between tadalafil and bosentan in healthy male subjects. J Clin Pharmacol. 2008;48:610-618.

53. Spence R, Mandagere A, Harrison B, Dufton C, Boinpally R. No clinically relevant pharmacokinetic and safety interactions of ambrisentan in combination with tadalafil in healthy volunteers. J Pharm Sci. 2009;98:4962-4974.

54. Palmieri EA, Affuso F, Fazio S, Lembo D. Tadalafil in primary pulmonary arterial hypertension. Ann Intern Med. 2004;141:743-744.

55. Tay EL, Geok-Mui MK, Poh-Hoon MC, Yip J. Sustained benefit of tadalafil in patients with pulmonary arterial hypertension with prior response to sildenafil: a case series of 12 patients. Int $J$ Cardiol. 2008; 125:416-417.

56. Bendayan D, Shitrit D, Kramer MR. Combination therapy with prostacyclin and tadalafil for severe pulmonary arterial hypertension: a pilot study. Respirology. 2008;13:916-918.

57. Faruqi S, Fathi H, Morice AH. Combination of sitaxentan and tadalafil for idiopathic pulmonary arterial hypertension following relapse on bosentan. Int J Cardiol. 2009 Jan 25. [Epub ahead of print]

58. Galiè N, Brundage BH, Ghofrani HA, et al; Pulmonary Arterial Hypertension and Response to Tadalafil (PHIRST) Study Group. Tadalafil therapy for pulmonary arterial hypertension. Circulation. 2009;119:2894-2903

59. Pepke-Zaba J, Beardsworth A, Chan M, Angalakuditi M. Tadalafil therapy and health-related quality of life in pulmonary arterial hypertension. Curr Med Res Opin. 2009;25:2479-2485.

60. Galiè N, Manes A, Negro L, Palazzini M, Bacchi-Reggiani ML, Branzi A. A meta-analysis of randomized controlled trials in pulmonary arterial hypertension. Eur Heart J. 2009;30:394-403.
Vascular Health and Risk Management

\section{Publish your work in this journal}

Vascular Health and Risk Management is an international, peerreviewed journal of therapeutics and risk management, focusing on concise rapid reporting of clinical studies on the processes involved in the maintenance of vascular health; the monitoring, prevention and treatment of vascular disease and its sequelae; and the involvement of

\section{Dovepress}

metabolic disorders, particularly diabetes. This journal is indexed on PubMed Central and MedLine. The manuscript management system is completely online and includes a very quick and fair peer-review system, which is all easy to use. Visit http://www.dovepress.com/ testimonials.php to read real quotes from published authors. 